ISSN 0103-5150

Fisioter. Mov., Curitiba, v. 30, n. 2, p. 287-296, Apr./June 2017

Licenciado sob uma Licença Creative Commons

DOI: http://dx.doi.org/10.1590/1980-5918.030.002.A009

(c) (i)

\title{
Clinical profile of patients with fibromyalgia syndrome
}

\section{Perfil clínico de pacientes com síndrome da fibromialgia}

\author{
Andrei Pereira Pernambuco ${ }^{[a, b, c]}$, Lorena Rodrigues Terra da Silva ${ }^{[a]}$, \\ Angélica Cristina Souza Fonseca ${ }^{[a]}$, Débora d'Ávila Reis ${ }^{[c]^{*}}$ \\ [a] Centro Universitário de Formiga (UNIFOR-MG), Formiga, Minas Gerais, Brazil \\ [b] Universidade de Itaúna (UIT), Itaúna, Minas Gerais, Brazil \\ [c] Universidade Federal de Minas Gerais (UFMG), Belo Horizonte, Minas Gerais, Brazil
}

\begin{abstract}
Introduction: The new diagnostic criteria for fibromyalgia (FM) include the presence of chronic, widespread pain associated with other symptoms such as fatigue, sleep disturbance, anxiety and depression. All these symptoms should be considered when thinking and clinical decision making of physiotherapists dealing with FM. However, it is clear that the other symptoms that accompany the pain are often neglected. Objective: To measure the levels of fatigue, sleep disturbances, anxiety and depression in patients with FM and compare them to levels found in healthy controls. Methods: Forty-six women diagnosed with FM and 30 healthy controls participated in the study. The levels of each of the symptoms were assessed by four validated questionnaires in Brazil (Piper Fatigue Scale - Revised, Pittsburgh Sleep Quality Index, Beck Anxiety Inventory and the Beck Depression Inventory). Statistical analysis was performed using GraphPad Prism software and all tests used a significance level of $5 \%(\alpha=0.05)$. Results: FM patients had significantly elevated levels of fatigue $(p=0.0005)$, sleep disturbances $(p=0.003)$, anxiety $(p=0.0012)$ and depression $(p=0.0003)$ compared to healthy controls. Symptoms fatigue and depression correlated strongly and positively with one another and with other symptoms evaluated. Conclusion: The other symptoms that comprise the clinical picture of FM need be considered not only in order to recover the health of patients, but above all in an attempt to preserve it and promote it.
\end{abstract}

Keywords: Fibromyalgia. Fatigue. Sleep. Anxiety. Depression.

\footnotetext{
* APP: PhD, e-mail: pernambucoap@gmail.com

LRTS: undergrad, e-mail: lorenarodsilva@hotmail.com

ACSF: undergrad, e-mail: angélica_cfonseca@yahoo.com

DAR: PhD, e-mail: debsdavila@gmail.com
} 
Resumo

Introdução: Os novos critérios de diagnóstico da fibromialgia (FM) contemplam a presença de dor crônica e generalizada associada a outros sintomas como fadiga, distúrbios do sono, ansiedade e depressão. Todos estes sintomas deveriam ser considerados durante o pensamento e tomada de decisão clínica de fisioterapeutas que lidam com a FM. Contudo, percebe-se que os demais sintomas que acompanham a dor são muitas vezes negligenciados. Objetivo: Mensurar os níveis de fadiga, distúrbios do sono, ansiedade e depressão em pacientes com FM e compará-los aos níveis encontrados em controles saudáveis. Métodos: Quarenta e seis mulheres com diagnóstico de FM e 30 controles saudáveis participaram do estudo. Os níveis de cada um dos sintomas foram avaliados por questionários validados no Brasil (Escala de Fadiga de Piper - Revisada, Índice de Qualidade do Sono de Pittsburgh, Inventário de Ansiedade de Beck e Inventário de Depressão de Beck). A análise estatística foi realizada no software GraphPadPrism e todos os testes utilizaram nível de significância de 5\% ( $\alpha=0,05)$. Resultados: As pacientes com FM apresentaram níveis significativamente elevados de fadiga $(p=0,0005)$, distúrbios do sono $(p=0,003)$, ansiedade $(p=0,0012)$ e depressão $(p=0,0003)$ quando comparadas a controles saudáveis. Os sintomas fadiga e depressão se correlacionaram fortemente e positivamente entre si e com os demais sintomas avaliados. Conclusão: Os demais sintomas que compõe o quadro clínico da FM precisam ser considerados não só no intuito de recuperar a saúde dos pacientes, mas, sobretudo na tentativa de preservá-la e promovê-la.

Palavras-chave: Fibromialgia. Fadiga. Sono. Ansiedade. Depressão.

\section{Introduction}

The fibromyalgia (FM) is considered a painful, chronic syndrome that occurs preferentially in women (1). According to statistics this health condition occurs from $2 \%$ to $4 \%$ of the world population and in spite of appearing in individuals of any age, it is observed that there is a great prevalence in people aging between 30 and 55 years old (2).

The first criteria of FM diagnosis were published in 1990 and it was observed the presence of generalized chronic and musculoskeletal pain associated to the presence of at least 11 tender points, which are anatomic bilateral sites to touching (3). Although they don't integrate the 1990 criteria, several other symptoms like stiffness, anxiety, depression, headaches, sleep disturbs, and fatigue were often presents in the clinical condition of FM (4). The high prevalence of the symptoms which come together with the pain in FM made these symptoms call more and more attention of the medical-scientific community (5 - 7). Thus, the importance of such symptoms was so great that in 2011 they were inserted in the new diagnosis criteria of the FM syndrome established by the American College of Rheumatology.

With the publication of the new criteria of diagnosis, the FM is no longer characterized only by the presence of a generalized and chronic pain and the analysis of the other symptoms associated to pain have become an essential element for both the diagnosis of this condition as well as for the following up of the clinical condition evolution (8). According to the new criteria, the generalized and chronic pain needs to be necessarily associated to other symptoms such as fatigue, sleep disturb and cognitive symptoms. Thus, currently, the FM diagnosis is given under the following situations: general pain index (GPI) $\geq$ $9(5,8)$ and symptom severity scale (SSS) $\geq 5$ or IGP between $3-6$ e SSS $\geq 9(5,8)$.

As it was mentioned, meaningful changes happened in the diagnosis criteria of FM $(3,8)$. However such changes could not be observed concerning with the physiotherapeutic policy to handle the FM. After all, the majority of the physiotherapists insist in disregarding the importance of the other symptoms associated to pain at the moment of the thinking and the clinical decision taking ( $9-11)$. The majority of the professionals continue focused in the musculoskeletal alterations only and in the pain relief, which in turns results in inefficient treatments before the clinical complexity and heterogeneity present in FM (9 - 11).

Based on the above text, the goal of this study was to measure the levels of fatigue, sleep disorder, 
anxiety and depression in patients with FM and compare them to the levels found in healthy controls.

\section{Methods}

\section{Ethical Aspects}

The stages of the Project, only were started after the approval of the research protocol by the Ethic Committee in Research in Humans of the Centro Univesitário de Formiga -MG (CEPH/UNIFOR-MG), by the legal opinion number 687.895. To participate of the research the subjects involved signed the free and informed consent (TCLE). This and other ethical concerns are in accordance with the terms of the Declaration of Helsinki version 2013 and of the Resolution 466/12 of the National Council of Health.

Type of study

An observational and transversal study was performed using the control group.

Patients

46 women with FM and 30 healthy women having age and body mass index (BMI) similar participated this study. The search for participants was done by means of advertisements in the newspapers, radio programs and pamphlets pasted in the Municipal Basic Health Care of Formiga, Minas Gerais. The sampling was performed by convenience and the first volunteers who matched the inclusion and exclusion criteria were applied for the study. After applying for the study, the patients with FM were undergone to a medical examination with specialists to confirm the FM diagnosis in accordance with the diagnosis criteria established by the American College of Rheumatology em 2011(8).

Inclusion and exclusion criteria

The inclusion criteria to the group of patients with FM were: women with FM diagnosis confirmed by a specialist, aging between 25 and 65 years old; BMI below $30 \mathrm{~kg} / \mathrm{m}^{2}$; signing of TCLE; not using medicines for more than three months or stable medical treatment for at least three months (12).

The exclusion criteria for the fibromyalgia group were: not signing in the TCLE; the absence in the data collecting session; using steroids or non-steroids antiinflammatory medicines over the last three months, pregnant ones; breast feeding ones; historic or presence of neoplasm; autoimmune, infect-contagious or psychiatric diseases beyond any pharmacological alteration within the three months before the data collection (12).

To compose the control group healthy women were recruited having in average aging and BMC similar to the ones found in the group of patients with FM; who were not using any kind of medicines; who haven't had neither medical family history with neoplasm nor with the presence of it, autoimmune, psychiatric, infectious or inflammatory diseases and that they agreed on signing the TCLE (12).

\section{Data collection}

All the volunteers were interviewed in a single moment by an experienced physiotherapist who has known the objectives of this study. To assess the symptoms the interviewer used four questionnaires with validity and reliability assured in Brazil.

\section{Data collection instruments}

Piper Fatigue Scale Revised (PFSR): It consists of a questionnaire which assesses the impact of fatigue on the individuals in the exact moment of its application. It is composed by 27 questions, though, only 22 questions are considered to the final scoring. Each of the questions should be answered with a number which varies from one to 10 . Being the smaller numbers indicating strong disagreement on the statement and the larger numbers indicating a strong agreement. The total punctuation in EFPR may vary from zero to 10 . To obtain the final score, one should add the obtained values in each of the 22 questions and, in sequence divide the result by the number of questions, in this case being 22 . The larger the result the bigger the impact on the fatigue of the individual (13).

The scores of seven components are summed and classified in the following way: zero to four "good sleep quality", five to 10 "bad sleep quality" and 10 
to 21 "presence of sleep disorders". In the PSQI, the higher the punctuation the worse the sleep quality of the individual (14).

The Pittsburg Sleep Quality Index (PSQI): It is a questionnaire which assesses the quality of sleep during the month prior to the date of the application. It is composed by 10 questions, being the first four ones opened and the others using multiple choice. All the questions make up seven components which can be attributed values from zero to three. The final punctuation may vary from zero to 21 points. Each component has a specific assessment: the first refers to the subjective quality of sleep; the second the latency of sleep; the third the duration of sleep; the fourth the habitual efficiency of sleep; the fifth the disorders of sleep; the sixth the use of medicines to sleep, and the seventh the dysfunction of sleep during the day.

Beck Anxiety Inventory (BAI): It assesses the intensity of the symptoms of anxiety of the individual taking into consideration the last week prior the questionnaire application. It is composed of 21 multiple choice questions which offer four kinds of answers which vary from the absence of symptoms (zero) to the presence of severe symptoms (three). The individual scores are summed and from the total score it is possible to classify the levels of anxiety in the following way: zero to seven points (minimum of anxiety); eight to 15 points (mild anxiety); 16 to 25 points (moderate anxiety) and 26 to 63 points (severe anxiety) (15).

Beck Depression Inventory (BDI): It proposes to assess the intensity of the depressive symptoms. It is composed by 21 questions with options for answers which vary from zero (absence of symptoms) to three (severe symptoms). The individual should mark the alternative which better describes his/her state in the week which preceded the application of the questionnaire. To obtain the final result is needed to sum all the individual scores. To the interpretation of the final score, the following situations should be considered: zero to nine (absence of depression): 10 to 16 (mild to moderate depression); 17 to 29 (state of moderate depression to severe one) and 30 to 63 (state of severe depression) (16).

\section{Statistics Analysis}

The Kolmogorov-Smirnov's test was used to check the data distribution. To assess the differences between the groups was used the Student's T test of Independence the parametric data and the MannWhitney test was used to the non-parametric ones. To performing these testes was used the SoftwareGraphpadPrism v.5.0, accepting the significance level 5\% $(\alpha=0.05)$.

After the application of tests, the results were presented by median \pm SD. To a better visualization of the results, they were presented in form of graphics and tables.

\section{Results}

The data on Table 1 show that both groups of the study are homogeneous regarding the age, weight, height, and BMC. In any of theses variables significant differences were observed between the group of patients with FM and the healthy control group.

As for the data obtained by "Piper Fatigue Scale Revised", the patients with FM obtained mean 6.49 \pm 2.0 points and median of 7.05 points, such values, according to the points of the cut of instrument refer to a moderate/severe fatigue level. Regarding to the healthy controls obtained mean $3.48 \pm 2.49$ 3.48 and median of 3.41 points what indicates mild fatigue. Comparing the two groups it was observed that the values found in patients with FM are significantly larger than those found in healthy controls $(p=0.0005)$ (Figure 1A). These results indicate that the patients with FM feel more fatigued that those of the healthy controls.

The results obtained by "Index of Sleep Quality of Pittsburg" showed that the mean obtained by patients with FM was $12.12 \pm 4.20$ points; and the median was of 12.5 points. These results demonstrate the presence of sleep disorders among the FM patients. As regard the healthy controls the mean found was $8.20 \pm$ 3.14 points and the median was of 8.01 points which indicates bad sleep quality. When the two groups of volunteers are compared, again significant statistics difference can be observed between the groups $(p=0.0033)$ (Figure 1B). The results show that FM patients own significantly a bad sleep quality than those of the healthy controls.

As regard to the anxiety assessed by "Beck's Anxiety Inventory" it was observed that the FM patients presented mean $22.88 \pm 10.92$ points and median of 22 points what represents moderate anxiety levels. As for the healthy controls present mean 
values of $11.13 \pm 10.82$ points and median of 9.01 points, indicating mild anxiety levels. Such difference again resulted in significant statistics intergroups, with the value of $p=0.0012$ (Figure 1C). These results show that the anxiety levels are higher in FM patients than those in healthy controls.

As regard to the depressive symptoms assessed by means of the "Beck Depression Inventory", they showed a mean of $24,12 \pm 11,54$ points and median of 22.5 points in the group of patients with FM. These values indicate moderate/severe depression levels in FM patients. The values found in the group of FM patients were significantly higher $(\mathrm{p}=0.0003)$ than those found in healthy controls that presented mean of $10,6 \pm 8,45$ points and median of 9.02 points suggesting the mild depression presence (Figure 1D). Such results mean that the FM patients present higher depression levels than those of the healthy controls.

In searching for existing correlations among the variables of interest in study, it was observed that the depression symptom as well as the fatigue symptom was correlated significantly and positively with all other symptoms investigated. The data refer to the analysis of correlation and are presented in Table 2.

Table $\mathbf{1}$ - Characteristics of the participants in the study

\begin{tabular}{cccc}
\hline & $\begin{array}{c}\text { Healthy controls } \\
(\mathbf{n}=\mathbf{3 0})\end{array}$ & $\begin{array}{c}\text { Patients with FM } \\
(\mathbf{n}=\mathbf{4 6})\end{array}$ & Value of $\mathbf{p}$ \\
\cline { 2 - 4 } & Median \pm SD & Median \pm SD & 0.48 \\
Weight & $45.33 \pm 8.05$ & $46.92 \pm 9.60$ & 0.99 \\
Height & $66.51 \pm 11.82$ & $66.51 \pm 10.47$ & 0.90 \\
BMC & $1.60 \pm 0.06$ & $1.60 \pm 0.06$ & 0.83 \\
\hline
\end{tabular}

Note: Test Results of T Independent regarding the differences intergroup in the variables of age, weight, height and BMC. Level of significance of $5 \%$.

A

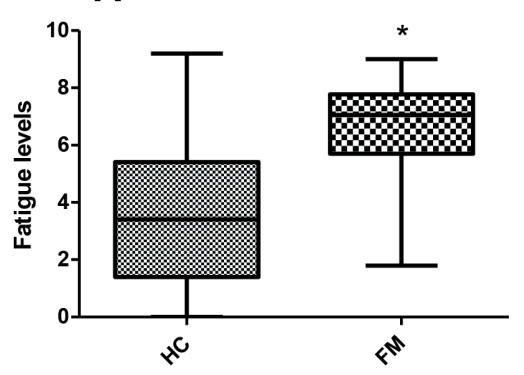

C

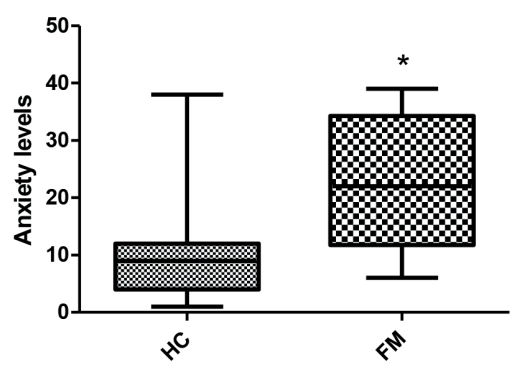

B

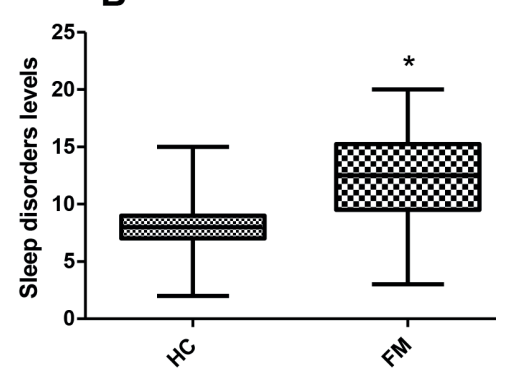

D

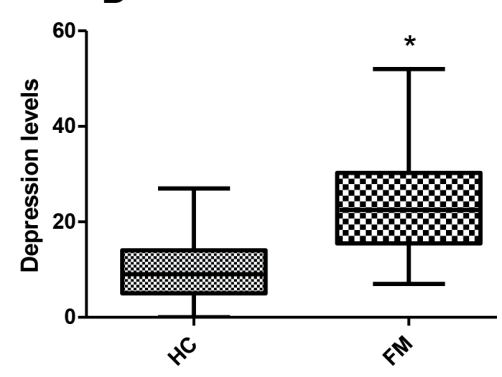

Figure 1 - Boxplot (Whiskers mín-máx) representing the fatigue level, sleep disorders, anxiety, and depression in health controls $(\mathrm{HC})$ and in fibromyalgia patients (FM) 
Table 2 - Correlation matrix among the variables of interest in study

\begin{tabular}{|c|c|c|c|c|c|c|}
\hline & & & Fatigue & Sleep & Anxiety & Depression \\
\hline \multirow[t]{8}{*}{ Correlation Test } & \multirow[t]{2}{*}{ Fatigue } & $r$ & 1.00 & 0.42 & 0.49 & 0.47 \\
\hline & & $p$ & - & $0.03^{*}$ & $0.01^{*}$ & $0.01^{*}$ \\
\hline & \multirow[t]{2}{*}{ Sleep } & $r$ & 0.42 & 1.00 & 0.19 & 0.40 \\
\hline & & $p$ & $0.03^{*}$ & - & 0.33 & $0.04^{*}$ \\
\hline & \multirow[t]{2}{*}{ Anxiety } & $r$ & 0.49 & 0.19 & 1.00 & 0.56 \\
\hline & & $p$ & $0.01^{*}$ & 0.15 & - & $0.00^{* \star}$ \\
\hline & \multirow[t]{2}{*}{ Depression } & $r$ & 0.47 & 0.40 & 0.56 & 1.00 \\
\hline & & $p$ & $0.01^{*}$ & $0.04^{*}$ & $0.00^{* *}$ & - \\
\hline
\end{tabular}

Note: *Values of $p \leq 0.05$ and ${ }^{* *}$ values of $p \leq 0.01$ - Significant correlation between the presented variable in the column and the variable present in line. The letter $p$ refers to the significance level obtained by the correlation test and the letter $r$ refers to the correlation coefficient between the variables.

\section{Discussion}

The main characteristic of FM is the presence of chronic and generalized pain (8). This symptom has already taken part of the first criteria of diagnosis in FM elaborated in 1990 by American College of Rheumatology (ACR) and still integrates the new diagnosis criteria of FM published in 2011 by ACR $(3,8)$. The pain in FM manifests in chronic form (duration longer than three months) and generalized (below and above the waist line) on the right and left sides of the body and with at least one point on the axial skeleton (3). The origin of the pain in FM has not been completely clear and a series of hypotheses try to explain this phenomenon. The main hypotheses involves: alteration in the ways of transmission of pain $(17,18)$, alterations in the levels of neurotransmitters $(12,19)$ and or biomarkers of the inflammatory process $(20,21)$. It becomes necessary to emphasize that the presence of pain may interfere on the manifestation of other symptoms, as well as the perception may be empowered in the presence of such symptoms (22).

Yet, in the present study, it was decided not to investigate the pain, like the majority of the studies do, but investigate the other symptoms which integrate the clinical condition of FM. These are the direct responsible ones by the vast clinical heterogeneity observed in patients with this condition $(1,8)$. It is important to highlight that these symptoms are constantly neglected in the moment of thinking and clinical decision-taking by part of physiotherapists (9 - 11), what may result in inefficient treatments and with low resoluteness of the services. In spite of the high prevalence of fatigue, sleep disorders, anxiety and depression among FM patients (1), such symptoms did not integrate the diagnosis criteria of FM up to the year 2011 (8). The simple fact of these symptoms now integrate the new criteria of FM diagnosis reflects an impacting change in the look of the medical-scientific community on this condition (23). Since up to the publication of the new criteria, the FM was considered a health condition characterized solely and exclusively by pain (3). And after the publication of the new criteria the pain has not been considered the only component to be assessed and the other symptoms that often accompanied it now receive equal importance in the composition of the clinical condition of FM $(8,23)$.

The results of this study show that FM patients present levels significantly high of fatigue, sleep disorders, anxiety and depression, when they are compared to health controls. Similar results have already been described in studies which searched to assess the prevalence of such symptoms among FM patients (12, 24 - 27). These findings suggest that the modification of the diagnosis criteria of FM with the valorization of other symptoms which accompany the pain was a wise strategy of American College of Rheumatology. Besides, it is demonstrated the importance of considering such symptoms in the moment of thinking and physiotherapeutic decision-taking based on the real needs of patients as it is recommended by the World Health Organization (28). Also it is important to emphasize that the fatigue levels, anxiety and depression and sleep disorders may be monitored, serving as indicators of the FM evolution over the time (8), contributing so to the following-up of the effects provided by the intervention. 
Presently, it has been observed that the physiotherapy policy for the FM treatment is ruled basically in analgesic and anti-inflammatory resources in order to provide pain relief to the patients $(9-11)$. It is still observed that the majority of times the other symptoms which accompany the pain are neglected during all process of assessment and physiotherapeutic intervention. This guidance of attention on a particular symptom rather than the others contradicts the bio-psycho social model assumptions proposed by WHO, since it fragments the patient and do not permit a broader and holistic look at the health and the developed aspects related to the health (28).

According to the results of the current study, the occurrence of a particular symptom, for instance, the fatigue and the depression, is able to impact directly in the manifestation of other symptoms which integrate the FM clinical condition. The data of Silva et al. (24) and Brandt et al. (25) corroborate the findings in the current study, since the authors also identified a strong significant and positive correlation among the sleep disorders, the fatigue and the depression. Moreover according to Silva et al. these symptoms interfere in the accomplishment of daily activities and the social participation of patients (24). Thus it is wise to say that these symptoms deserve the same attention given to the pain during the physiotherapeutic procedures, for, they may influence negatively the clinical condition of this bringing hazards to the aspects related to the human functionality as it has already been demonstrated in other studies $(12,24$ - 27).

Another point to be considered is the fact that should the physiotherapy continue to guide its policies exclusively on the diagnosis (medical model), its scope will be doomed to the failure (29). After all, it is known that the people with the same diagnosis, in this case FM, may present different symptoms, impairments in the body structure and functions as well as the activity limitations and restrictions in participating, regardless all these variables may be influenced in a distinct way by contextual factors (environmental and personal) pertinent the reality where these people are inserted $(30,31)$. So all these health components should be considered with the same importance, since besides being results of a already installed condition, in this case FM, may also be responsible for the arising and evolution of a new disease (32).

It is also needed to consider that the physiotherapy focused only in the treatment of diseases may be seen as a setback, after all the physiotherapy may no longer be seen as a profession focused exclusively in the rehabilitation being of fundamental importance which can be explored all potential of this profession, not only concerning with the health recovery but also on the prevention processes and health promoting occupying mainly with the functionality and quality of people's life (33). To occur this change in paradigms, new approaches to the patient should be considered. In the context, the health education programs (HEP) emerge as good alternatives to the handle of chronic condition such as the FM (34). This kind of intervention is able to stimulate behaviors of prevention, of promoting and of recovery of health by their participants (34 - 36). The HEP may also transmit information and incentive skills which allow that the participant himself take decisions and is able to improve his health condition and also his close people's or those that share the same health condition (34). Moreover, the scientific evidences stand that the using of this kind of intervention in FM patients may result not only in the improvement of life quality, symptoms presentation, functionability, social functions and mental health $(34,35)$, but also in objective markers of immunologic and neuroendocrine activity such as the cortisol concentrations and of anti-inflammatory citocines (37), variables able to interfere objectively in the manifestation and or the evolution of different symptoms which compose the FM syndrome including the pain, fatigue, anxiety, depression and sleep disorders $(12,20)$.

The main limitations of this study refer to the fact that FM is a condition extremely clinically heterogeneous what means that patients having the same diagnosis, many times they present distinct symptomatology. Besides, the questionnaires used do not permit the assessment of the volunteer of the research in the biopsicosocial context, as WHO suggests. After all instruments used in spite of validated, focus only in the aspects of body functions failing in approaching the body structure, the activity, and the participation and the environmental factors which contribute for the functionality and or incapacity of the individual. Another limitation in the study is related to the fact that the association among the symptoms which compose the clinical condition of FM was done only in the transversal form and only a longitudinal study will be able to the association over the time. In this sense it is also important to mention that the pain levels have not been monitored in 
this study what impedes the analysis of the relation between the symptom and other variables of interest in the study.

\section{Conclusion}

The FM is not characterized only by pain, but also by other symptoms which manifest very frequent and with high intensity. This way, when thought in effective physiotherapeutic policies to the FM it is necessary to consider the approach of other symptoms that associate to the chronic and generalized pain, mainly fatigue and depression which seem to play an important role in the clinical presentation of FM. Fatigue and depression may interfere directly in the manifestation of other symptoms like anxiety and sleep disorders worsening even more the clinical condition of these patients. Thus the other symptoms which follow the pain in the FM syndrome should be considered in the moment of thinking and clinical decision taking not only with the intention of recovering the patient's health but also in the tentative of preserving and promoting it. The findings of this study support the study of new researches in order to search the longitudinal association between these variables, the pain and the FM. Besides, transversal and longitudinal studies with the objective of assessing the effect in the treatment of several symptoms which follow the pain in FM should be encouraged.

\section{Acknowledgements}

The authors thank to CNPq and to UNIFOR-MG for the financial support and for the logistic support offered to this research.

\section{References}

1. Bellato E, Marini E, Castoldi F, Barbasetti N, Mattei L, Bonasia DE, et al. Fibromyalgia syndrome: etiology, pathogenesis, diagnosis, and treatment. Pain Res Treat. 2012;2012:426130.

2. Sarzi-Puttini P, Atzeni F, Di Franco M, Buskila D, Alciati A, Giacomelli C, et al. Dysfunctional syndromes and fibromyalgia: a 2012 critical digest. Clin Exp Rheumatol. 2012;30(6 Suppl 74):143-51.
3. Wolfe F, Smythe HA, Yunus MB, Bennett RM, Bombardier C, Goldenberg DL, et al. The American College of Rheumatology 1990 Criteria for the Classification of Fibromyalgia. Report of the Multicenter Criteria Committee. Arthritis Rheum. 1990;33(2):160-72.

4. Toda K. The modification of the american college of rheumatology preliminary diagnostic criteria for fibromyalgia should be supplemented and revised. J Rheumatol. 2011;38(9):2075; author reply 2076.

5. Wolfe F. How to use the new American College of Rheumatology fibromyalgia diagnostic criteria. Arthritis Care Res (Hoboken). 2011;63(7):1073-4.

6. Toda K. Preliminary diagnostic criteria for fibromyalgia should be partially revised: comment on the article by Wolfe et al. Arthritis Care Res (Hoboken). 2011;63(2):308-9; author reply 309-10.

7. Wolfe F, Rasker JJ. The Symptom Intensity Scale, fibromyalgia, and the meaning of fibromyalgia-like symptoms. J Rheumatol. 2006;33(11):2291-9.

8. Wolfe F, Haüser W. Fibromyalgia diagnosis and diagnostic criteria. Ann Med. 2011;43(7):495-502.

9. Ricci NA, Dias CN, Driusso P. A utilizacao dos recursos eletrotermofototerapeuticos no tratamento da sindrome da fibromialgia: uma revisao sistematica. Rev Bras Fisioter. 2010;14(1):1-9.

10. Ferreira LL, Marino LHC, Cavenaghi S. Recursos eletrotermofototerapêuticos no tratamento da fibromialgia. Rev Dor. 2011;12(3):256-60.

11. Batista JS, Borges AM, Wibelinger LM. Tratamento fisioterapêutico na síndrome da dor miofascial e fibromialgia. Rev Dor. 2012;13(2):170-4.

12. Pernambuco AP, Schetino LP, Viana RS, Carvalho LS, d'Avila Reis D. The involvement of melatonin in the clinical status of patients with fibromyalgia syndrome. Clin Exp Rheumatol. 2015;33(1 Suppl 88):S14-9.

13. Mota DDCF, Pimenta CAM, Piper BF. Fatigue in Brazilian cancer patients, caregivers, and nursing students: a psychometric validation study of the Piper Fatigue Scale-Revised. Support Care Cancer. 2009;17(6):645-52.

14. Backhaus J, Junghanns $\mathrm{K}$, Broocks A, Riemann D, Hohagen F. Test-retest reliability and validity of the Pittsburgh Sleep Quality Index in primary insomnia. J Psychosom Res. 2002;53(3):737-40. 
15. Beck AT, Brown GD, Epstein N, Steer RA. An inventory for measuring clinical anxiety: psychometric properties. Clin Psychol. 1988;56(6):893-7.

16. Gorenstein C, Andrade L. Validation of a Portuguese version of the Beck Depression Inventory and the State-Trait Anxiety Inventory in Brazilian subjects. Braz J Med Biol Res. 1996;29(4):453-7.

17. DeSantana JM, Sluka KA. Central mechanisms in the maintenance of chronic widespread noninflammatory muscle pain. Curr Pain Headache Rep. 2008;12(5):338-43.

18. Fleming KC, Volcheck MM. Central sensitization syndrome and the initial evaluation of a patient with fibromyalgia: a review. Rambam Maimonides Med J. 2015;6(2):e0020.

19. Cordero MD, Alcocer-Gomez E, Cano-Garcia FJ, de Miguel M, Sanchez-Alcazar JA, Moreno Fernandez AM. [Low levels of serotonin in serum correlates with severity of fibromyalgia]. Med Clin (Barc). 2010;135(14):644-6. Spanish.

20. Pernambuco AP, Schetino LP, Alvim CC, Murad CM, Viana RS, Carvalho LS, et al. Increased levels of IL-17A in patients with fibromyalgia. Clin Exp Rheumatol. 2013;31(6 Suppl 79):S60-3.

21. Carvalho LS, Correa H, Silva GC, Campos FS, Baiao FR, Ribeiro LS, et al. May genetic factors in fibromyalgia help to identify patients with differentially altered frequencies of immune cells? Clin Exp Immunol. 2008;154(3):346-52.

22. Arnold LM, Leon T, Whalen E, Barrett J. Relationships among pain and depressive and anxiety symptoms in clinical trials of pregabalin in fibromyalgia. Psychosomatics. 2010;51(6):489-97.

23. Salaffi F, Sarzi-Puttini P. Old and new criteria for the classification and diagnosis of fibromyalgia: comparison and evaluation. Clin Exp Rheumatol. 2012;30(6 Suppl 74):3-9.

24. Silva LC. Presença de fadiga, hiperalgesia corporal, distúrbios do humor e do sono em pacientes com migrânea, fibromialgia ou fibromigrânea [master's thesis]. Recife (Brazil): Universidade Federal de Pernambuco; 2012. Portuguese.

25. Brandt R, Fonseca ABP, Oliveira LGAd, Steffens RdAK, Viana MdS, Andrade A. Perfil de humor de mulheres com fibromialgia. J Bras Psiquiatr. 2011;60(3):216-20.
26. Santos EB, Quintans Jr LJ, Fraga BP, Macieira JC, Bonjardim LR. Avaliação dos sintomas de ansiedade e depressão em fibromiálgicos. Rev Esc Enferm USP. 2012;46(3):590-6.

27. Ferro CV, Ide MR, Streit MV. Correlação dos Distúrbios do Sono e Parâmetros subjetivos em indivíduos com fibromialgia. Fisioter Mov. 2008;21(1):33-8.

28. OMS. Towards a Common Language for Functioning, Disability and Health - ICF. Geneva: World Health Organization; 2002.

29. Sabino GS, Coelho CM, Sampaio RF. Utilização da Classificação Internacional de Funcionalidade, Incapacidade e Saúde na avaliação fisioterapêutica de indivíduos com problemas musculoesqueléticos nos membros inferiores e região lombar. Acta Fisiatr. 2008;15(1):24-30.

30. Prodinger B, Salzberger T, Stucki G, Stamm T, Cieza A. Measuring functioning in people with fibromyalgia (FM) based on the international classification of functioning, disability and health (ICF) - a psychometric analysis. Pain Pract. 2012;12(4):255-65.

31. Prodinger B, Cieza A, Williams DA, Mease P, Boonen A, Kerschan-Schindl K, et al. Measuring health in patients with fibromyalgia: content comparison of questionnaires based on the International Classification of Functioning, Disability and Health. Arthritis Rheum. 2008;59(5):650-8.

32. OMS. Classificação Internacional de Funcionalidade, Incapacidade e Saúde. São Paulo: EDUSP; 2003. Portuguese.

33. Brasil ACO. Promoção de saúde e a funcionalidade humana. Rev Bras Promoc Saude. 2013;26(1):1-4.

34. Souza JB, Bourgault P, Charest J, Marchand S. Escola inter-relacional de fibromialgia: aprendendo a lidar com a dor - estudo clínico randomizado. Rev Bras Reumatol. 2008;48(4):218-25.

35. Burckhardt CS. Educating patients: self-management approaches. Disabil Rehabil. 2005;27(12):703-9.

36. Mannerkorpi K, Henriksson C. Non-pharmacological treatment of chronic widespread musculoskeletal pain. Best Pract Res Clin Rheumatol. 2007;21(3):513-34. 
Pernambuco AP, Silva LRT, Fonseca ACS, Reis DA.

37. Pernambuco AP. Impacto de um programa de educação em saúde sobre aspectos neuroimunocomportamentais de pacientes com diagnóstico de fibromialgia [dissertation]. Belo Horizonte (Brazil): Universidade Federal de Minas Gerais; 2014. Portuguese.

Received in 05/14/2015

Recebido em 14/05/2015

Approved in 07/28/2016

Aprovado em 28/07/2016 